\title{
David Newsome \& Ross K. Dowling (dir.), Geotourism: The tourism of Geology and Landscape
}

Goodfellow Publishers, 2010, 320 pages

Philippe Bachimon

\section{CpenEdition}

\section{Journals}

Édition électronique

URL : http://journals.openedition.org/tourisme/435

DOI : $10.4000 /$ tourisme.435

ISSN : 2492-7503

\section{Éditeur}

Éditions touristiques européennes

Édition imprimée

Date de publication : 1 juin 2012

Pagination : 103-104

ISSN : 2109-5671

Référence électronique

Philippe Bachimon, «David Newsome \& Ross K. Dowling (dir.), Geotourism: The tourism of Geology and Landscape », Mondes du Tourisme [En ligne], 5 | 2012, mis en ligne le 30 septembre 2015, consulté le 22 septembre 2020. URL : http://journals.openedition.org/tourisme/435 ; DOI : https://doi.org/10.4000/ tourisme.435

Ce document a été généré automatiquement le 22 septembre 2020.

\section{c) $(1) \ominus$}

Mondes du tourisme est mis à disposition selon les termes de la licence Creative Commons Attribution - Pas d'Utilisation Commerciale - Pas de Modification 4.0 International. 


\section{David Newsome \& Ross K. Dowling (dir.), Geotourism: The tourism of Geology and Landscape}

Goodfellow Publishers, 2010, 320 pages

Philippe Bachimon

\section{RÉFÉRENCE}

David Newsome \& Ross K. Dowling (dir.), Geotourism: The tourism of Geology and Landscape, Goodfellow Publishers, 2010.

1 Cet ouvrage collectif, dirigé par deux professeurs australiens (des universités Murdoch et Edith-Cowan, de Perth) se présente comme une somme de seize contributions originales sur la question du géotourisme, auxquelles s'adjoignent une introduction et une conclusion rédigées par les codirecteurs.

2 La richesse de cet ouvrage tient dans la diversité de ses 34 auteurs qui s'avèrent être principalement des universitaires australiens, auxquels se sont adjoints des chercheurs venus de Finlande, de Nouvelle-Zélande, du Royaume Uni, d'Allemagne, de Pologne et des États-Unis. La diversité des approches, assez inégales cependant en termes d'approfondissement des analyses, voire de pertinence à la thématique, est aussi un point fort de l'ouvrage. Ainsi on va de l'inventaire géologique à l'auscultation d'expériences menées en géotourisme dans le cadre par exemple de l'Islande, du mont Vésuve, de la Nouvelle-Zélande et, bien entendu, de l'Australie, qui fournit le principal référentiel. L'interprétation paysagère est aussi analysée en détail lorsqu'elle est présente dans le cadre d'aires protégées. Au final, l'ouvrage apparaît très bien documenté et très agréable à lire.

3 L'un de ses principaux apports se trouve dans le chapitre d'introduction, dans lequel une définition du géotourisme est avancée par les coordinateurs ; ceux-ci proposent de le considérer comme "un aspect du tourisme de nature qui s'intéresse particulièrement à la 
géologie et au paysage", qui comprendrait "le tourisme des géosites et la conservation de la géo-diversité ainsi que la compréhension des sciences de la terre à travers l'expérience et l'apprentissage" et qui se matérialiserait "dans la visite de sites géologiques remarquables, la pratique des circuits géologiques, des points d'observation paysagers, des tours guidés, des activités géologiques et la participation aux centres d'interprétation implantés sur les géosites". Cette définition très large (certains diront trop ?) a le mérite de mettre en perspective la spécificité de pratiques innovantes au regard d'autres plus classiques comme celles de l'écotourisme, du tourisme d'aventure et du tourisme culturel. En fin d'ouvrage, un texte important, de Ross Dowling et de David Newsome, revient d'ailleurs sur ce précepte en ouvrant une réflexion sur l'avenir du géotourisme qui, sortant peu à peu de la confidentialité, devient un produit dans lequel l'approche naturaliste scientifique d'origine évolue vers une interprétation plus culturelle. C'est bien entendu la question de la mise en visite des sites qui interroge les auteurs, autant que leur multiplicité et leur diversité. Elle est mise en avant dans les deux objectifs principaux que se propose l'ouvrage, à savoir d'arriver à une uniformisation de la définition du terme "géotourisme" et à une prise de conscience plus large de l'importance de l'héritage géologique.

4 Si nous avions à formuler des réserves (non géologiques !) on noterait que l'ouvrage méconnait l'exemple français, qui se limite il est vrai à deux sites reconnus par l'Unesco, mais surtout l'exemple de la Chine qui à elle seule possède 22 des 65 géoparcs existant dans le monde... alors qu'elle n'est quasiment pas abordée dans l'ouvrage. Pour avoir dirigé des travaux de recherche doctorale sur le l'unique géoparc français et sur une aire paysagère chinoise, je me demande s'il n'y a pas là quelques lacunes embarrassantes, découlant d'un certain "australocentrisme". Car ignorer ce qui se fait en Chine dans les "mises en parc", qui ont consisté parfois en un déménagement forcé de minorités ethniques sous le prétexte de naturaliser des sites afin qu'ils soient ouverts ensuite à un tourisme de masse grâce à de lourds aménagements, n'est certes pas neutre. En matière de développement local et de bonne gouvernance, il y aurait bien des problèmes urgents à aborder d'un point de vue scientifique, que l'on retrouve à des degrés divers dans bien d'autres géosites.

5 À la décharge des auteurs, notons que les questions des risques managériaux et environnementaux sont traitées de manière particulièrement pertinente dans beaucoup d'articles. En particulier dans celui de Christof Pforr et Andreas Megerle qui propose une grille d'évaluation du système d'acteurs du géotourisme telle qu'elle a pu être testée au Bade-Wurtemberg (Allemagne) ou encore dans celui de Lisa M. King sur le "géotourisme" dans les îles Hawaïennes.

6 Au final, il s'agit d'un ouvrage particulièrement intéressant qui propose un essai de conceptualisation de la question et un état des lieux, forcément provisoire dans la mesure où ce tourisme, qui tend à se développer rapidement, le fait parfois avec beaucoup d'amateurisme et d'atteintes à la ressource. Les pratiques de pillage continu des coraux dans les lagons polynésiens ou des fossiles dans le Haut Atlas au Maroc, pour ne prendre que ces exemples non abordés dans l'ouvrage, par les touristes ou des marchands de souvenirs sont en effet très inquiétantes pour le stock minéral, du moins dans sa partie facilement accessible, et finalement pour la durabilité de destinations géotouristiques en émergence. 


\section{AUTEURS}

PHILIPPE BACHIMON

Université d'Avignon 